\title{
AVALIAÇÃO DA APRENDIZAGEM NA EDUCAÇÃO SUPERIOR VERSUS AVALIAÇÃO DO DESEMPENHO
}

\author{
EVALUATION OF LEARNING IN HIGHER EDUCATION VERSUS \\ PERFORMANCE ASSESSMENT
}

\author{
EVALUACIÓN DEL APRENDIZAJE EN LA EDUCACIÓN SUPERIOR VERSUS \\ EVALUACIÓN DEL RENDIMIENTO
}

\author{
Neide Pena Cária ${ }^{1}$, Elieser Castro Paiva ${ }^{2}$
}

\begin{abstract}
RESUMO
O estudo está vinculado à Linha de Pesquisa Práticas Educativas e Formação do Profissional Docente e ao Grupo de Pesquisa GPEG, cadastrado no CNPq. Tem-se como objetivo central analisar a perspectiva de aprendizagem, voltada para o desenvolvimento de competências, que norteia o processo de avaliação de desempenho do estudante da educação superior e suas relações com as perspectivas de avaliação propostas na LDB n 9394/1996, no Plano nacional de Educação (PNE 2014-2024) e na Lei n. ${ }^{\circ}$ 10.861/2004 que institucionalizou o ENADE, juntamente com o Sistema Nacional de Avaliação Superior (SINAES). O SINAES é formado por três componentes principais: a) a avaliação das instituições; b) avaliação dos cursos; c) avaliação do desempenho dos estudantes. São questionados os aspectos teóricos e conceituais que aproximam ou distanciam, teórica e conceitualmente, as expressões "avaliação da aprendizagem" e "avaliação de desempenho" e são exploradas nos atos legais as relações entre os significados dos termos "aprendizagem", “desempenho" e "competências". Metodologicamente, adotouse a pesquisa documental e uma pesquisa bibliográfica sobre o tema avaliação, buscando compreender as mudanças que ocorreram nos modelos de avaliação, tendo em vista as finalidades da educação superior no contexto que se delineou após a década de 1990 e, principalmente, após a publicação da LDB, em vigor. A política de avaliação é um tema que vem conquistando grande espaço na área educacional e no campo da pesquisa, sendo reconhecida a sua função social, política e educacional. Este presente estudo não desconsidera os inúmeros questionamentos não favoráveis ao processo de avaliação pelo seu caráter regulatório. Porém, no contexto governamental, como política de avaliação institucionalizada, o ENADE se firma como um dos elementos balizadores importante, que atua de forma integrada no que se refere à qualidade e relevância dos cursos de graduação e das Instituições de Ensino Superior, juntamente com o SINAES.
\end{abstract}

PALAVRAS-CHAVE: Avaliação da aprendizagem. Avaliação de desempenho. Educação Superior. Qualidade de ensino.

\footnotetext{
${ }^{1}$ Doutora em Educação, com área de concentração em Currículo, pela Pontífícia Universidade Católica de São Paulo (PUC/SP, 2012). Atua na Proreitoria de Graduação da Univás. É Docente do Programa de Pós Graduação Stricto Sensu/Mestrado em Educação na Univás/MG. É coordenadora e professora do curso de pós-graduação Lato Sensu em gestão educacional na Univás/MG.

${ }^{2}$ Mestrado em Educação
} 


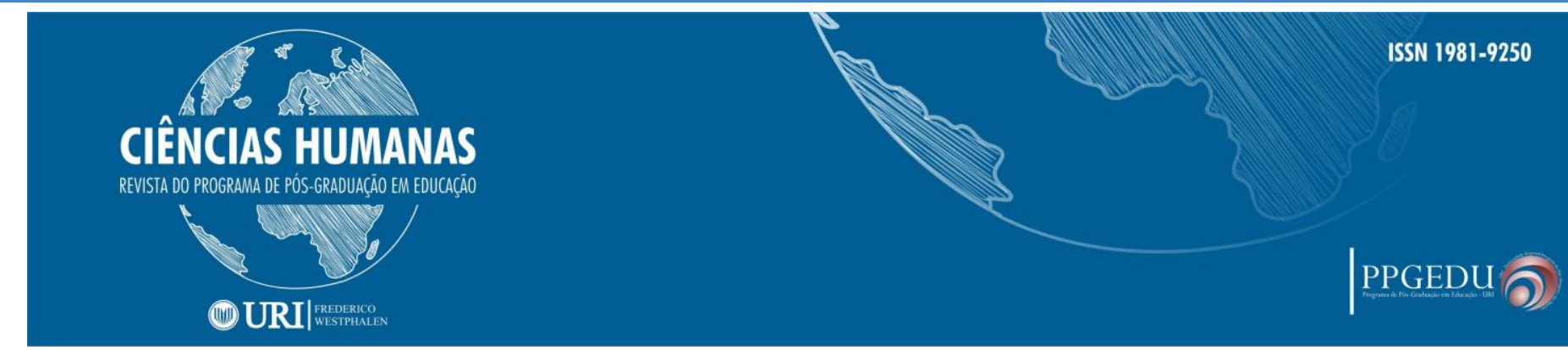

\section{ABSTRACT}

The study is linked to the Educational Practices and Teacher Training Research Line and, to the GPEG Research Group, which is registered in the Cap. The main research objective is to analyze the learning perspective, regarding the skills development, which guides the evaluation process of student performance in higher education and its relation with the assessment prospects proposed by the LDB $\mathrm{n}^{\circ}$ 9394/1996, in the National Education Plan (PNE 2014-2024) and, in the Law n. 10.861 / 2004, which has institutionalized the ENADE, together with the National Higher Education Assessment System (known as SINAES). SINAES consists of three main components: a) institutions' evaluation; b) course evaluation; c) student performance evaluation. Were questioned the theoretical and conceptual aspects that bring closer or pull away, theoretically and conceptually, the expressions "learning assessment" and " performance assessment" and, are explored within the legal acts, the relation between the meanings of expressions as "learning", "performance" and "skills". Methodologically, it was chosen the documentary research and a bibliographic research on the assessment subject, seeking to understand the changes that occurred in the evaluation models, in view of the purposes of higher education in the context that was delineated after the 1990s and, mainly, after the LDB publication, in force. Evaluation policy is a topic that has been gaining a larger space in the educational area and in the field of research, being recognized its social, political and educational function. This study does not disregard the innumerable questionings not favorable to the assessment process due to its regulatory nature. However, in the governmental context, as an institutionalized assessment policy, ENADE has established itself as one of the important guiding elements, operating in an integrated way with regard to the quality and relevance of undergraduate courses and of Higher Education Institutions, together with SINAES.

KEYWORDS: Learning assessment. Performance assessment. Higher Education. Teaching quality.

\section{RESUMEN}

El estudio está vinculado a la Línea de Investigación de Prácticas Educativas y Formación Docente y, al Grupo de Investigación GPEG, que está registrado en el CNPq. El objetivo principal de la investigación es analizar la perspectiva de aprendizaje, en relación con el desarrollo de habilidades, que guía el proceso de evaluación del desempeño de los estudiantes en educación superior y su relación con las perspectivas de evaluación propuestas por el LDB nº 9394/1996, en el Plan Nacional de Educación (PNE). 2014-2024) y, en la Ley No. 10.861 / 2004, que ha institucionalizado la ENADE, junto con el Sistema Nacional de Evaluación de la Educación Superior (conocido como SINAES). El SINAES consta de tres componentes principales: a) evaluación de las instituciones; b) evaluación del curso; c) Evaluación del desempeño del alumno. Se cuestionaron los aspectos teóricos y conceptuales que acercan o alejan, teórica y conceptualmente, las expresiones "evaluación de aprendizaje" y "evaluación de desempeño" y, se exploran dentro de los actos jurídicos, la relación entre los significados de expresiones como "aprendizaje", "rendimiento" y "habilidades". Metodológicamente, se eligió la investigación documental y una investigación bibliográfica sobre el tema de la evaluación, buscando comprender los cambios que se produjeron en los modelos de evaluación, en vista de los propósitos de la educación superior en el contexto delineado después de la década de 1990 y, principalmente, después de la publicación LDB, en vigor. La política de evaluación es un tema que ha ido ganando un espacio más amplio en el área educativa y en el campo de la investigación, siendo reconocida su función social, política y educativa. ENADE es un instrumento importante para evaluar el desempeño nacional de los estudiantes en relación con el contenido del programa, el desarrollo de habilidades y habilidades necesarias para profundizar la educación general y profesional; proporciona indicadores de calidad con respecto al nivel de competencias desarrolladas en los cursos y puede ayudar al maestro a identificar el nivel de aprendizaje del estudiante a través de los resultados de su desempeño en las múltiples modalidades de evaluación. En este momento, el examen es obligatorio y la situación de regularidad del estudiante debe aparecer en sus registros escolares. La periodicidad de esta evaluación es trienal para cada área de conocimiento e integra el SINAES. Este estudio no ignora los innumerables cuestionamientos no favorables al proceso de evaluación debido a su naturaleza reguladora. Sin embargo, en el contexto gubernamental, como una política de evaluación institucionalizada, ENADE se ha consolidado como uno de los elementos orientadores importantes, que opera de manera integrada con respecto a la calidad y la relevancia de los cursos de pregrado y de las instituciones de educación superior, junto con SINAES. 
PALABRAS CLAVE: Evaluación del aprendizaje. Evaluación del desempeño. Educación más alta. Calidad docente.

\section{CONSIDERAÇÕES INICIAIS}

$\mathrm{O}$ artigo, que ora se apresenta, origina-se de uma pesquisa documental e uma revisão de literatura sistematizada para a dissertação de Mestrado em Educação. Tem-se como objetivo apresentar parte da análise que relacionou avaliação de aprendizagem no ensino superior com avaliação de desempenho do estudante, que é realizada via ENADE. Instituído pela Lei no 10.861/2004, o ENADE é um dos três pilares do Sistema Nacional de Avaliação da Educação Superior (SINAES) que visa promover a avaliação de instituições, avaliação de cursos e avaliação de desempenho dos estudantes, na direção de assegurar a melhoria da qualidade do ensino.

O trabalho de análise se concentrou em identificar a perspectiva de avaliação que é adotada pelo ENADE, fazendo aproximações entre "avaliação de aprendizagem" e "avaliação de desempenho", a partir da seguinte interrogação: o que esses processos têm em comum e o que os distanciam? Significariam as duas expressões a mesma coisa? Para fazer essa discussão, o texto aqui apresentado se baseia no histórico da trajetória da avaliação e na pesquisa documental, tomando como amparo teórico a Lei ${ }^{\circ}$ 10.861/2004, a LDB no 9394/1996 e a Base Nacional Curricular Comum (BNCC) do Ensino médio e dados que se referem ao ENADE e ao SINAES, como instrumentos de avaliação que buscam a melhoria da qualidade da educação superior e da formação profissional, conforme segue.

\section{ASPECTOS HISTÓRICOS DA AVALIAÇÃo}

No contexto histórico da avaliação existem diversos relatos de formas diferentes de se avaliar que foram utilizados ao longo dos anos. Pode-se considerar que o modelo atual da avaliação escolar é parte deste contexto evolutivo das formas avaliativas das diferentes fases históricas, a saber: Idade Antiga, Idade Média, Renascimento, Modernidade e Idade Contemporânea. 


\section{CIÊNCIAS HUMANAS}

REVISTA DO PROGRAMA DE PÓS-GRADUAĞ̈O EM EDUCAĞ̄o

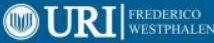

Ao tratar da temática da avaliação da aprendizagem, é preciso considerar que muito já foi discutido e avançado nessa área, mas a concepção de avaliação e a sua prática ainda continua presa a modelos tradicionais no dia a dia das instituições de ensino, de todos os níveis, com sentido atrelado à escola e à educação. Embora o termo "avaliação" tenha surgido como "exame" (FERNANDES, 2009), de modo mais abrangente, a avaliação não diz respeito somente ao processo de ensino, mas sim, faz parte da atividade humana. No entanto, ao se falar em avaliação, somos logo remetidos à educação ou à escola.

Conforme Carminatti e Borges (2012, p. 165), o termo "avaliação" faz emergir alguns sinônimos como: abalançamento, cálculo, estimativa, ajuizamento, ponderação, valorização, mensuração, medição, dentre outros. Assim entendendo a avaliação, a autora afirma que ela se constitui em um processo intencional, auxiliado por diversas ciências e que se aplica a qualquer prática e, por isso, é possível falar na avaliação das diversas atividades profissionais, como de uma empresa, de um programa, de uma política.

Conforme descreve Fernandes (2009), recorrendo a alguns autores como Kellangan e Madaus (2003), o autor afirma que os exames parecem ter-se iniciado há cerca de 2.500 anos na China, para selecionar pessoal militar e funcionários públicos procurando, simultaneamente. Essa avaliação visava evitar que a seleção fosse feita com base em laços familiares dos candidatos com diferentes dignitários dos poderes instituídos. Por algum tempo, na China, o sistema de avaliação era conhecido como exame e continuou sendo utilizado para selecionar pessoas a cargos públicos. Na idade antiga, tribos primitivas utilizavam provas e os adolescentes somente após passarem por essas provas e serem aprovados, era aceito nas tribos como guerreiros ou adultos.

Desde os tempos primitivos, em algumas tribos, os jovens só passavam a serem considerados adultos após terem sido aprovados em uma prova referente aos seus usos e costumes. Na Grécia, Sócrates submetia seus alunos a um questionário oral, método utilizado por muitos professores até os dias atuais, "o conhece-te a ti mesmo" (SÓCRATES) onde a autoavaliação é uma conjectura com a verdade. Outra forma de avaliação era realizada através de exercícios orais utilizados pelas universidades 


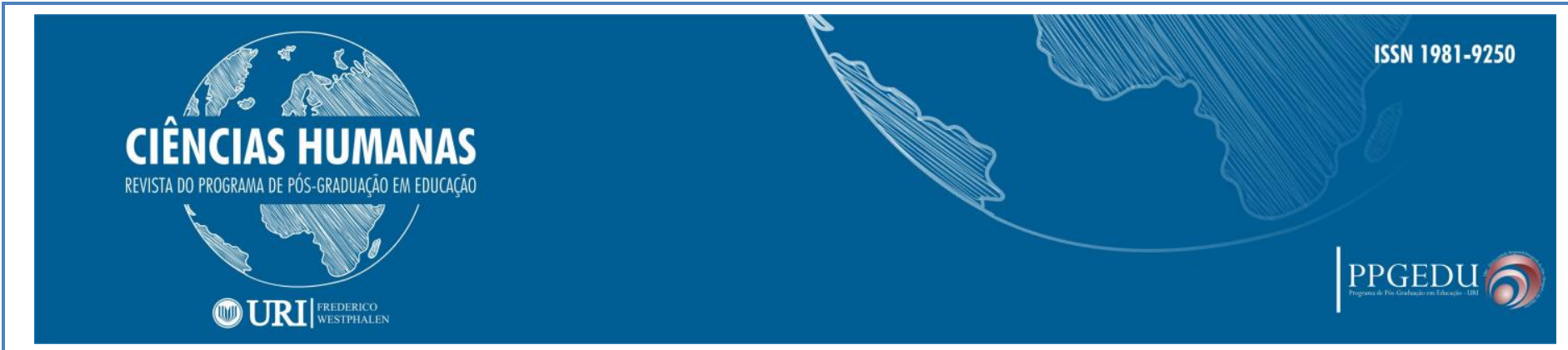

medievais e mais tarde pelos jesuítas. Na Idade Média, aceitava-se quase passivamente a opinião dos mestres ou autoridades no assunto e, assim, repetir, integralmente o que se ouvia ou lia, era a prova do saber.

\section{AVALIAÇÃO NA CONTEMPORANEIDADE}

A avaliação começa a assumir uma forma mais estruturada apenas depois do século XVIII, onde começaram a serem formadas as primeiras escolas modernas e os livros passaram a serem acessíveis a todos e criaram-se as bibliotecas. À época, avaliação ficou associada à ideia de exames e controle, constituindo dessa forma a área de estudos chamada "docimologia". A docimologia clássica punha ênfase no aperfeiçoamento das técnicas de construção dos instrumentos de avaliação e de análise de resultados, centrando-se na avaliação como um comportamento, procurando determinar, experimentalmente, os mecanismos intervenientes na decisão avaliativa, tais como: reação dos aplicadores, reação dos submetidos aos exames, discrepâncias entre situações de exame e entre critérios de aplicadores.

Vasconcellos, em entrevista ao site PORVIR, afirma que o período que vai do século 11, quando ocorre a retomada das cidades e surgem as universidades, até o século 16, existia uma organização da escola elementar muito ligada à universidade. Assim, era possível ir da gramática ao doutorado sem nunca repetir de ano. Para o autor, existia um ciclo inicial, para dominar os instrumentos da leitura; depois vinha o ciclo intermediário, das artes liberais, para formar o homem livre em contraponto ao homem manual. E o terceiro ciclo dava conta da teologia, medicina e direito, as áreas nas quais era possível se tornar mestre ou doutor. Somente século XV vai surgir a seriação com as escolas dos irmãos da vida comum, nos Países Baixos. Eram escolas com até 2.500 alunos e a seriação era feita para organizá-las. De acordo com autor, no século XVI, juntam-se as duas coisas: o exame e a seriação. A partir daí, acontece a repetência, sobretudo do $1^{\circ}$ ao $5^{\circ}$ ano.

Conforme Lima (2010) foi na Idade Contemporânea, compreendida entre o fim do século XVII ao século XX, que surge a necessidade de se construir um sistema educativo inteiramente novo no qual a educação da criança passa ao domínio exclusivo e absorvente do Estado. No entendimento do autor, no início do século XVII ocorreu 


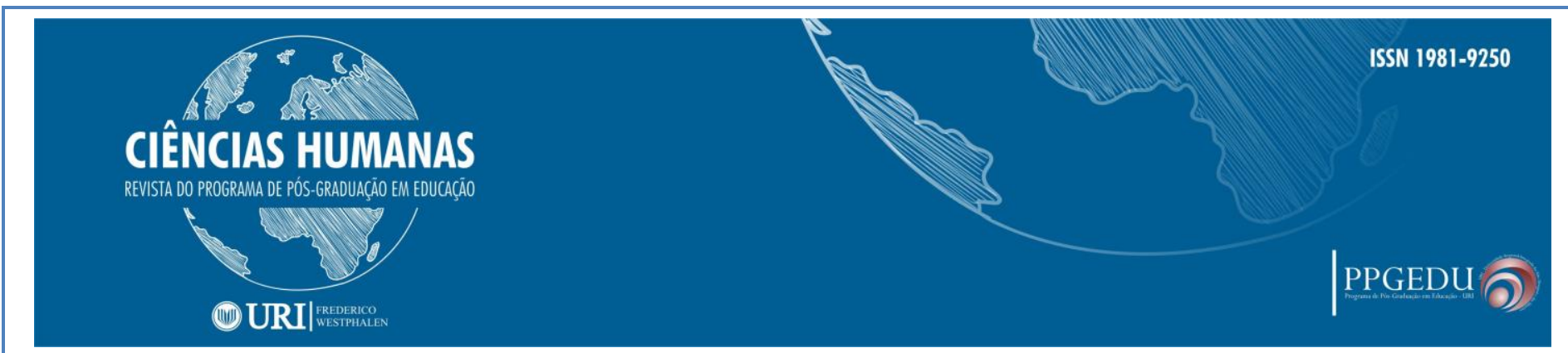

uma forte reação contra o ensino humanista tradicional, surgindo o laicismo e uma forte influência das ideias materialistas e anticlericais do racionalismo, do Enciclopedismo e do Naturalismo, predominando até o fim do século XVII essa reação contra o ensino vigente. Nos séculos XIX e XX predominaram as seguintes correntes pedagógicas: o individualismo, o socialismo, o nacionalismo e pragmatismo.

\section{AVALIAÇÃO NO SÉCULO XX: NASCE A IDEIA DO TESTE}

Como descrito por Abramowicz (1996), ainda hoje a avaliação sofre influências das correntes tradicionais, dando fundamentos a um grande número de teorias educacionais ao longo dos anos. A avaliação começa a assumir uma forma mais estruturada apenas depois do século XVIII, onde começaram a serem formadas as primeiras escolas modernas, os livros passaram a serem acessíveis a todos e criaram-se as bibliotecas. Nesta época devido à utilização de exames como forma de avaliação, esta ficou associada à ideia de exames, notação e controle, constituindo dessa forma a área de estudos chamada docimologia. Foi a partir do início do século XX que passaram a predominar as tendências pedagógicas que colocaram em primeiro plano o problema técnico da educação. A autora descreve que, no final do século XIX até parte do século $\mathrm{XX}$, destaca-se o uso da psicometria, caracterizada por testes padronizados e objetivos que mediam a inteligência e o desempenho das pessoas. No entanto, com o passar do tempo, a utilização desses testes veio sendo substituída por formas mais amplas de avaliar em que o aluno começava a ser visto como um todo, um ser humano com todas as suas implicações.

Para a autora, o termo "avaliação educacional" foi proposto primeiramente por Tyler, em 1934, na mesma época em que surgiu a educação por objetivos, que tem como princípio formular objetivos e verificar se estes foram cumpridos por meio de avaliação. Quando, nos Estados Unidos, já surgiam novas abordagens sobre a avaliação educacional como uma reação à noção de avaliação, como sinônimo de medida, e valorizada especialmente por suas características de objetividade, fidedignidade e possibilidade de manipulação matemática dos dados (STUFFLEBEAM, 1971), no

\begin{tabular}{c|c|c|c}
\hline Rev. Ciências Humanas & Frederico Westphalen, RS & Pg. 04 - 26 & Set./dez. 2018 \\
\hline Recebido em: $21 / 11 / 2018$ & Aceito em: 04/01/2019 \\
\hline
\end{tabular}




\section{CIÊNCIAS HUMANAS}

REVISTA DO PROGRAMA DE PÓS-GRADUAĞ̈O EM EDUCAĞ̄o

\section{(1) URI|}

Brasil, ainda se seguia a concepção positivista de avaliação expressa no modelo de Tyler, sem maiores críticas.

Ao longo do século XX, a tecnologia educacional foi se firmando como uma maneira nova de pensar a educação, de fazer frente aos problemas educacionais e avaliar a aprendizagem. Com o passar dos anos, a avaliação passou a ser obrigatória a todos os programas sociais e educativos dos EUA. Foi dessa maneira que a avaliação passou a fazer parte de outras áreas como filosofia, sociologia, economia e administração, ocorrendo a profissionalização da avaliação na década de 1960 até o início década de 1980. Segundo Abramowicz (1996), vários autores deram nomes aos diferentes enfoques da avaliação, porém todos eles valorizavam os métodos qualitativos e tinham uma visão democrática da avaliação, levando em conta a participação e a negociação. Assim, a partir de 1980, surge um novo rumo no campo da avaliação, nos EUA e na Inglaterra, que se espalham pelos demais países. Na última década do século $\mathrm{XX}$, o Estado assume um caráter mais controlador e fiscalizador e ocorrem também mudanças na avaliação até chegar à conformação atual, voltada para a utilização de métodos quantitativos, colocando em discussão a real finalidade da avaliação.

\section{GERAÇÕES DE AVALIAÇÃO: OUTRA FORMA DE CONTAR A HISTÓRIA}

$\mathrm{Na}$ literatura é possível identificar como os significados atribuídos à avaliação evoluíram ao longo da história, sempre adaptando as suas funções ao contexto histórico, sendo considerada por Guba e Lincoln, na década de 1980, como uma questão complexa, devido às várias mudanças que seu conceito adquiriu ao longo dos anos. Guba e Lincoln (1989), citado por Fernandes (2005) identificam quatro gerações na avaliação sobre as quais passamos a destacar: 1) A avaliação como medida; 2) A avaliação como descrição; 3) A avaliação como juízo de valor e 4) A avaliação como negociação e construção. A essa quarta geração tem sido dada atenção nos últimos anos, conforme passamos a apresentar em seguida.

\section{A PRIMEIRA GERAÇÃO DE AVALIAÇÃO}




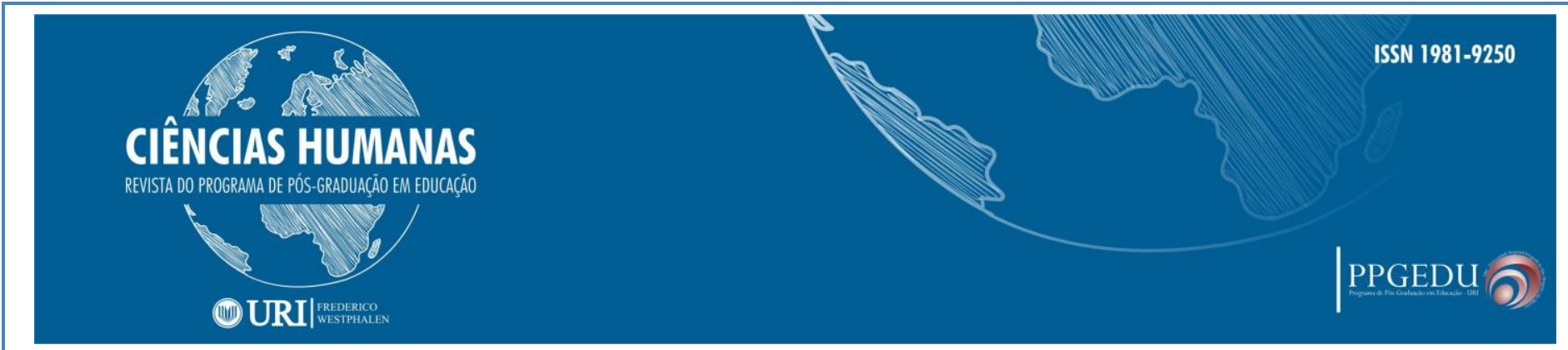

A primeira geração (Até a década de1930) considerava a avaliação como "medida" e inspira-se nos testes, desenvolvidos em França por Alfred Binet, destinados a medir a inteligência e as aptidões. Esta avaliação acabou por ser adotada pelos sistemas educativos no início do século XX, como sinônimo de medida. A avaliação era, portanto, uma questão fundamentalmente técnica em que através de testes bem construídos, era possível medir com rigor e isenção as aprendizagens escolares dos alunos. Nessa geração de geração, os conhecimentos são o único objeto de avaliação e o avaliador tem o papel técnico de elaborar testes previamente validados e de mensurar o que está sendo avaliado (GUBA; LINCOLN, 1989, p. 56).

Fernandes (2009, p. 2) descreve o contexto da primeira geração de avaliação identificada por Guba e Lincoln (1989):

No século XIX, com a importância atribuída a medida científica, desenvolvese a psicometria. São determinantes os trabalhos de Francis Galton e Alfred Binet. Galton, de nacionalidade francesa, admitindo que existe uma correlação entre as capacidades sensoriais, passíveis de serem medidas, e a inteligência, constrói e aplica testes para medir diferenças individuais de aptidão mental; Binet, de nacionalidade inglesa, orienta o seu trabalho no sentido do estudo global do indivíduo e cria um teste para despistar alunos com deficiências mentais.

Segundo Fernandes (2009), no início do século XX, nos Estados Unidos, com os estudos de Edward L. Thorndike acerca dos testes educacionais teve origem a concepção da avaliação como processo de quantificação.

\section{A SEGUNDA GERAÇÃO DE AVALIAÇÃO}

A segunda geração (1930 a 1945) está relacionada à taxionomia dos objetivos em que o avaliador tem um papel de "descrição", ele descreve critérios e padrões. Ao descrever critérios e padrões ele está preparando o instrumental para comparar o desempenho com os objetivos. Segundo Guba e Lincoln (1989, p. 56), Ralph Tyler é o autor mais influente dessa geração de avaliação. A medida deixou de ser sinônimo de avaliação e passou a ser um dos meios ao seu serviço. A principal diferença em relação à geração anterior reside na formulação de objetivos comportamentais e na verificação 


\title{
CIÊNCIAS HUMANAS
}

REVISTA DO PROGRAMA DE PÓS-GRADUAĞ̈O EM EDUCAĞ̄o

\section{(1) URI|}

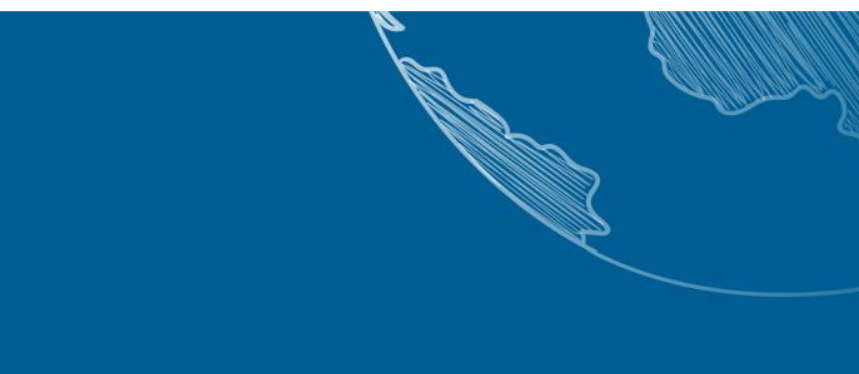

da sua consecução pelos alunos. A avaliação passa a ter uma função reguladora apesar da sofisticação teórica e prática que se lhe atribui atualmente.

Fernandes (2005, p. 2) descreve o contexto da primeira geração de avaliação identificada por Guba e Lincoln (1989):

\begin{abstract}
Nos anos vinte do século vinte, é desenvolvido um plano de investigações dirigidas por Ralph Tyler intitulado Eight Year Study of Secondary Education em escolas secundárias americanas na pretensão de elaborar novos currículos com ênfase na relação ensino-aprendizagem. No final da década de 1930 Ralph W. Tyler considerando que a avaliação não deve ser apenas uma unidade de medida e introduz novos conceitos associados à avaliação.
\end{abstract}

Como relatado por Fernandes (2005), mais tarde Tyler, por volta da década de 1950, procurava desestabilizar a ideia de mensuração na avaliação. Sua concepção contrapunha a ideia de que avaliação é sinônimo de aplicação de testes com lápis e papel. No entanto, Tyler não descartava a importância da aplicação dos testes, apenas acreditava que existiam outras maneiras de se constatar as mudanças comportamentais, denominadas aprendizagem. Ele defendia a inclusão de uma variedade de procedimentos avaliativos, tais como: teste, escalas de atitude, inventários, questionários, fichas de registros de comportamento e outras de coletar evidências sobre o rendimento dos alunos em uma perspectiva longitudinal, com relação à concepção de objetivos curriculares (TYLER, 1949)

\section{A TERCEIRA GERAÇÃO DA AVALIAÇÃO}

A terceira geração (Após 1946) passou a considerar a avaliação como “julgamento" ou "juízo de valor". É no âmbito desta geração de avaliação que surgem ideias como: a avaliação deve induzir e/ou facilitar a tomada de decisões que regulem o ensino e as aprendizagens; a recolha de informação deve ir para além dos resultados que os alunos obtêm nos testes; a avaliação tem de envolver os professores, os pais, os alunos e outros intervenientes; os contextos de ensino e de aprendizagem devem ser tidos em conta no processo de avaliação; a definição de critérios é essencial para que se 


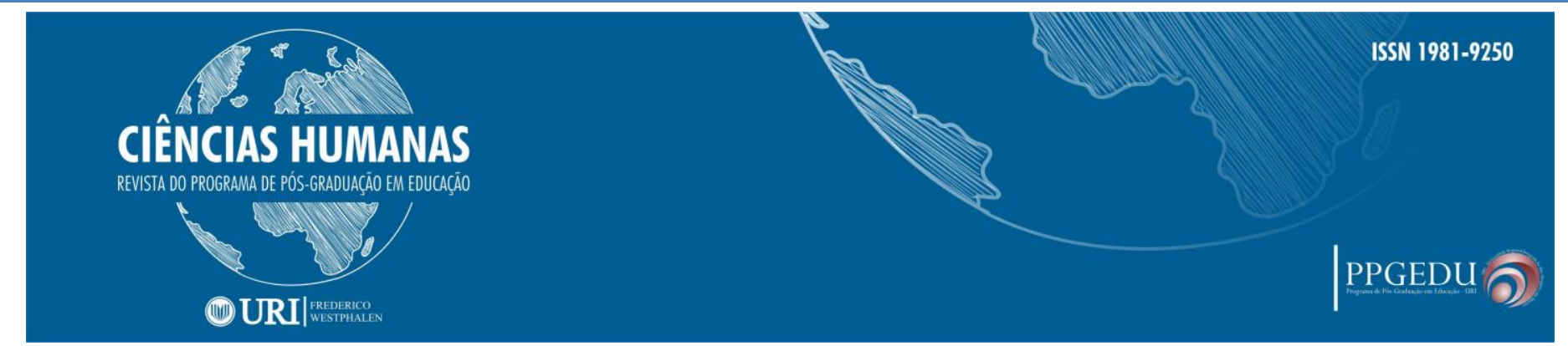

possa apreciar o mérito e o valor de um dado objeto de avaliação. Verifica se aquelas ações estão condizentes com uma determinada visão de mundo.

Fernandes $(2005$, p. 2) descreve o contexto da primeira geração de avaliação identificada por Guba e Lincoln (1989):

O lançamento do primeiro Sputnik, em 1957 pela União Soviética gera nos Estados Unidos da América uma onda de debates acerca dos currículos e do modo como são desenvolvidos. Questionam-se os conteúdos programáticos e põem-se em causa os métodos de ensino.

Na educação, conforme o autor, se revela na ideia de que o avaliador é um juiz e o juiz faz um juízo de valor.

\section{A QUARTA GERAÇÃO DE AVALIAÇÃO}

Sobre a quarta geração, Guba e Lincoln (2011), apresentam uma crítica aos três modelos anteriores, especificamente, à terceira geração, pois apresenta a avaliação enquanto julgamento, o que para eles pressupõe um tipo de autoritarismo embutido no processo de avaliação, trazendo a avaliação como um processo de negociação.

Ainda segundo Guba e Lincoln (2011), a avaliação como um processo de negociação é um movimento novo que caracteriza esse processo de transição e comunicar, negociar são elementos fundamentais nesse contexto atual, afinal todo mundo negocia, cada um tem que negociar no mundo do trabalho, com a comunidade, no espaço familiar e em todas as etapas do processo educativo. O papel do avaliador é de negociador, por meio de um processo de comunicação, que define previamente os critérios, os objetivos, as estratégias de avaliação que será realizada.

Guba e Lincoln encaram a sua quarta geração como uma geração de ruptura, a qual se caracteriza por não estabelecer parâmetros ou enquadramentos. Estes são definidos através de um processo de negociação entre aqueles que estão, de alguma forma, envolvidos na avaliação. Em simultâneo, trata-se de uma geração de avaliação de referência construtivista, não só pela metodologia que é posta em prática, como também

\begin{tabular}{c|c|c|c}
\hline Rev. Ciências Humanas & Frederico Westphalen, RS & Pg. 04 - 26 & Set./dez. 2018 \\
\hline \multicolumn{2}{c|}{ Recebido em: 21/11/2018 } & Aceito em: 04/01/2019 \\
\hline
\end{tabular}




\section{CIÊNCIAS HUMANAS}

REVISTA DO PROGRAMA DE PÓS-GRADUAĞ̈O EM EDUCAĞ̄o

\section{(1) URI|}

pela epistemologia que lhe está subjacente. Nesse processo, o avaliador tem que envolver os diversos segmentos interessados no objeto que está sendo avaliado e no final precisa divulgar os resultados obtidos, além de disseminar os resultados para que os mesmos tenham efeito em toda a comunidade envolvida. Essa geração pressupõe uma avaliação que envolva todos os atores envolvidos no processo, principalmente o aluno que nunca participou da avaliação.

Conforme Fernandes (2005, p. 2), Guba e Lincoln (1989) propuseram uma quarta geração de avaliação, de ruptura epistemológica com as anteriores, que responderá às dificuldades detectadas nas três gerações anteriores.

Guba e Lincoln encaram a sua quarta geração como uma geração de ruptura, a qual se caracteriza por não estabelecer parâmetros ou enquadramentos. Estes são definidos através de um processo de negociação entre aqueles que estão, de alguma forma, envolvidos na avaliação. Em simultâneo, trata-se de uma geração de avaliação de referência construtivista, não só pela metodologia que é posta em prática, como também pela epistemologia que lhe está subjacente.

Com o exposto, cabe destacar a percepção de Fernandes (2005) de que o conceito de avaliação é decorrente da sua caminhada histórica e parece que os seus "fantasmas" ainda se apresentam como forma de controle e de autoritarismo por diversas gerações, tornando-se difícil acreditar num processo avaliativo que é mais eficaz e capaz de melhorar o processo de ensino- aprendizagem.

\section{FUNÇÕES DA AVALIAÇÃO}

A concepção de avaliação como um processo contínuo e paralelo ao processo de ensino e aprendizagem deu origem à utilização de algumas modalidades de avaliação, a saber: a) Diagnóstica: utilizada no início do processo; pretende averiguar a posição do aluno face a novas aprendizagens que lhe vão ser propostas e a aprendizagens anteriores que servem de base àquelas, no sentido de obviar as dificuldades futuras e, em certos casos, de resolver situações presentes.

b) Formativa: utilizada no decorrer do processo; permite constatar se os alunos estão, de fato, atingindo os objetivos pretendidos, verificando a compatibilidade entre tais 


\section{CIÊNCIAS HUMANAS}

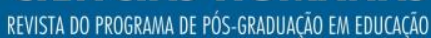

\section{(1) URI|}

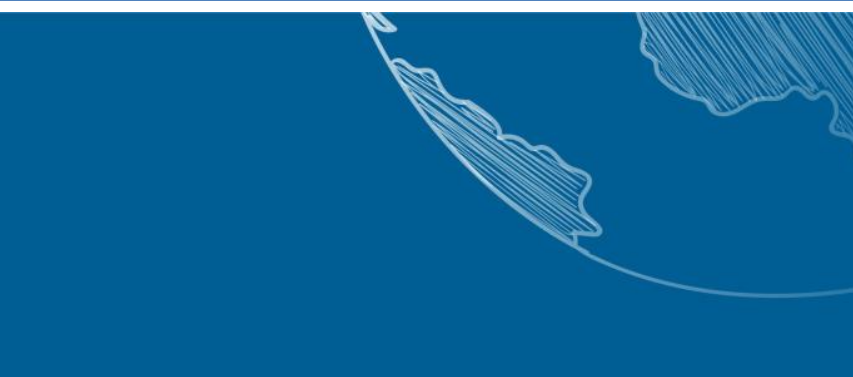

objetivos e os resultados efetivamente alcançados durante o desenvolvimento das atividades propostas.

c) Somativa: utilizada no final do processo; permite determinar o grau de domínio do aluno em uma área de aprendizagem e tem o propósito de classificar os alunos ao final de um período de aprendizagem, de acordo com os níveis de aproveitamento (HAYDT, 1995).

Conforme Fernandes (2009), as funções da avaliação mais tradicionalmente referidas por muitos autores são as funções formativa e somativa.

No caso, a tradicional avaliação psicométrica privilegia a função somativa, isto é, “a formulação de juízos acerca das aprendizagens dos alunos após um período mais ou menos longo de ensino e de atividades conducentes à aprendizagem" (FERNANDES, 2009, p. 92). De acordo com o autor, trata-se de uma concepção que tende a dar mais relevância às funções de classificação, de ordenação, de seleção ou de certificação e, por isso mesmo, não dá destaque à qualidade dos processos de aprendizagem nem aos contextos em que esta se desenvolve.

Já no caso da avaliação formativa, Fernandes (2009, p. 92) descreve que ela se desenvolve durante os períodos em que ocorrem o ensino e todas as atividades a ele associadas. Associa-se a uma concepção que se preocupa com os processos de ensino e aprendizagem, "que são analisados in loco, com plena integração da avaliação nesses mesmos processos; com criteriosa seleção de tarefas que motivem e mobilizem os alunos com o envolvimento, tão ativo quanto possível, na aprendizagem e na sua avaliação".

Fernandes (2009, p. 93) ressalta que "qualquer processo de avaliação tem de se considerar os processos e os produtos de aprendizagem". Para o autor, "é muito importante que a avaliação ajude a motivar os alunos para aprenderem com compreensão e para lhes dar conta de seus progressos e de seus sucessos, mas também de seus insucessos e dificuldades" (FERNANDES, 2009, p. 93).

Diante de novos paradigmas em educação, o grande desafio para construir novos caminhos é uma avaliação com critérios de entendimento reflexivo, conectado, compartilhado e autonomizador no processo ensino/aprendizagem, que deve contemplar 


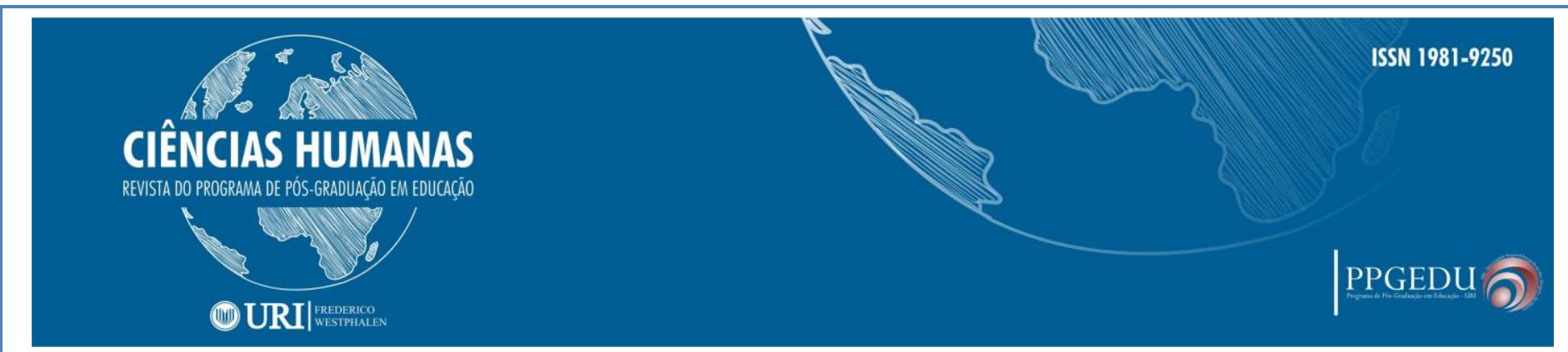

o qualitativo, valorizando a essência e a totalidade do processo educativo, como explica Fernandes (2009). É preciso superar o paradigma da avaliação como aprovação ou reprovação e da nota tendo um fim em si mesmo, distanciando-se da relação com as situações de ensino e aprendizagem.

Segundo Perrenoud (1998), no paradigma atual, a avaliação da aprendizagem é um processo mediador na construção do currículo e se encontra intimamente relacionada à gestão da aprendizagem dos alunos; requer preparo técnico e grande capacidade de observação dos profissionais envolvidos. O autor ressalta que, na avaliação da aprendizagem, o professor não deve permitir que os resultados das provas periódicas, geralmente de caráter classificatório, sejam supervalorizados em detrimento de suas observações diárias, de caráter diagnóstico. O professor, que trabalha numa dinâmica interativa, tem noção, ao longo de todo o ano, da participação e produtividade de cada aluno, pois a prova é somente uma formalidade do sistema escolar.

Na análise da Lei de Diretrizes e Bases (LDB), nº 9394, de 1996, em vigência, observa-se que o processo avaliativo é tratado como verificação do rendimento escolar. A lei estabelece que devem ser observados os seguintes critérios: a) Avaliação contínua e cumulativa do desempenho do aluno, em que prevaleça os aspectos qualitativos sobre os quantitativos e dos resultados ao longo do período sobre os de eventuais provas finais; b) Possibilidade de aceleração de estudos para alunos com atraso escolar; c) Possibilidade de avanços nos cursos e nas séries mediante verificação do aprendizado; d) Aproveitamento de estudos concluídos com êxito; e) Obrigatoriedade de estudo de recuperação, de preferência paralelos ao período letivo, para os casos de baixo rendimento escolar a serem disciplinados pelas instituições de ensino em seu regimento.

Observa-se que a Lei usa a expressão "verificação do rendimento escolar" referindo-se à avaliação da aprendizagem. Verificar, numa de suas acepções, quer dizer comprovar; rendimento pode ser entendido como eficiência. Então de acordo com a lei, cabe à escola comprovar a eficiência dos alunos nas atividades. Ou seja, avaliar o êxito por eles alcançado no processo de ensino aprendizagem é a função da avaliação. Mas, quando se trata em comprovar esse êxito, avaliar se torna complexo e, daí surge diversos questionamentos. Avaliar não é a mesma coisa que medir, quanto mais eu 


\section{CIÊNCIAS HUMANAS}

REVISTA DO PROGRAMA DE PÓS-GRADUAĞ̈O EM EDUCAĞ̄o

\section{(1) URI|}

preciso de instrumentos mais exatos para a medida mais ocorre o afastamento ao conceito qualitativo de aprendizagem. Como percebido na literatura visitada, no percurso da pesquisa que origem a este artigo, ao contrário disso não há instrumento preciso para a avaliação. Na avaliação da aprendizagem não se avalia um objeto concreto observável e, sim, um processo humano contínuo.

Como afirma Fernandes (2009, p. 93), o que normalmente fazemos é avaliar amostras de desempenhos dos alunos, relativamente domínios previstos no currículo, na sequência da resolução de tarefas de natureza diversa, porém "não é possível avaliar tudo o que um aluno sabe e é capaz de fazer". Atualmente os objetivos da avaliação visam tanto o processo de aprendizagem quanto os sucessos ou fracassos dos estudantes. Nesse sentido, a avaliação tem função legitimadora da ideologia das sociedades modernas. Os bons resultados acadêmicos são vistos como indicadores das aptidões que darão ao indivíduo possibilidades de progredir e ter êxito. No entanto, recentemente o interesse está concentrado em reduzir os efeitos negativos da avaliação no sistema escolar e sua repercussão individual sobre os estudantes.

\section{AVALIAÇÃO DE COMPETÊNCIAS NO ENSINO SUPERIOR}

A expansão do ensino superior no Brasil e as novas demandas do mercado de trabalho exercem considerável pressão sobre a formação de profissionais e isso se encontra materializado nas diretrizes curriculares nacionais e nos demais atos legais que regulamentam a educação superior, inclusive nas políticas de avaliação.

Em 1996, com a publicação da Lei de Diretrizes e Bases para a Educação (LDB), $n^{\circ}$ 9.394, em seu artigo 46, consolida-se a avaliação da educação superior, quando submete a autorização e o reconhecimento de cursos, bem como o credenciamento de instituições de educação superior, ao processo regular de avaliação, os quais deverão ser renovados, periodicamente, após processo de avaliação.

É possível observar que, ao longo dos anos o processo de avaliação foi se aperfeiçoando e, em 2004, o MEC, por meio da Lei 10.861, de 14 de abril de 2004, foi 


\section{CIÊNCIAS HUMANAS}

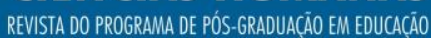

\section{(1)URI|}

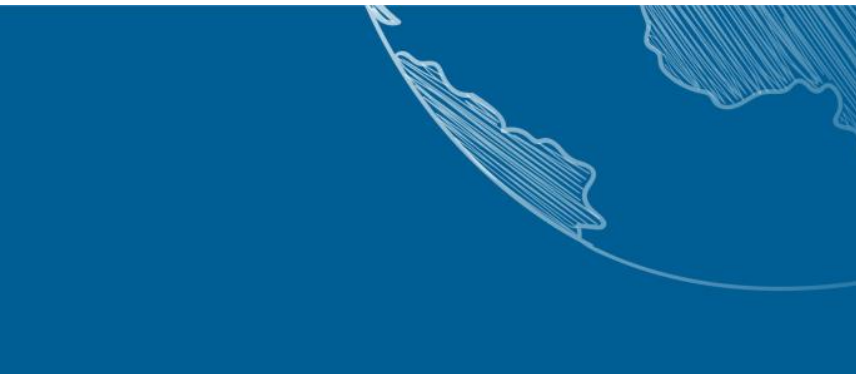

instituído o Sistema Nacional de Avaliação da Educação Superior (Sinaes), sobre o qual é apresentado a seguir.

\section{AVALIAÇÃO COMO MONITORAMENTO DA FORMAÇÃO PROFISSIONAL}

No cenário de um novo mundo produtivo e econômico, o mercado de trabalho passou a exigir um profissional capaz de lidar com uma realidade - local e global, com serviços cada vez mais especializados em que prevalece o uso de tecnologias, sendo também a remuneração variável e meritocrática. Nesse cenário, ao longo das últimas décadas, houve um aumento crescente do número de desempregados e, muitos passaram a trabalhar como autônomos, exigindo, cada vez mais, uma maior qualificação profissional, o que refletiu diretamente no setor educacional no que se refere à preparação de profissionais para o mundo produtivo, o que já foi reconhecido nas políticas de educação no documento da nova LDB nº 9394, publicada em 1996.

Com base na LDB, cabe ressaltar que, entre as finalidades da educação superior, predomina a formação para o mercado de trabalho e, por isso, os educadores devem reconhecer a força dessas tendências e reconhecer as suas implicações na formulação e limitações de políticas e práticas para a educação superior.

Considerando as finalidades da educação superior nas diretrizes da educação, já apresentadas neste texto, é preciso não desvincular a avaliação educacional das mesmas e nem as finalidades das instituições de ensino superior, tendo em vista os vínculos de ambas com o mercado de trabalho, em coerência com a tendência global que vem exigindo reformas e uma reconfiguração do ensino superior. Todavia, também, é preciso levar em conta que o processo de educação do ser humano é contínuo e, por isso, está atrelado à educação básica, ou seja, uma sólida formação desde a base.

Pelo cenário atual das pesquisas em avaliação no ensino superior, fica clara a necessidade de aprofundar pesquisas e conhecimentos o tema avaliação, considerando a sua integração no processo educativo, uma vez que uma avaliação aplicada de forma equivocada aos estudantes de graduação pode atingir a sua formação e, consequentemente, a sua atuação no mundo do trabalho. No entanto, o que se observa, 


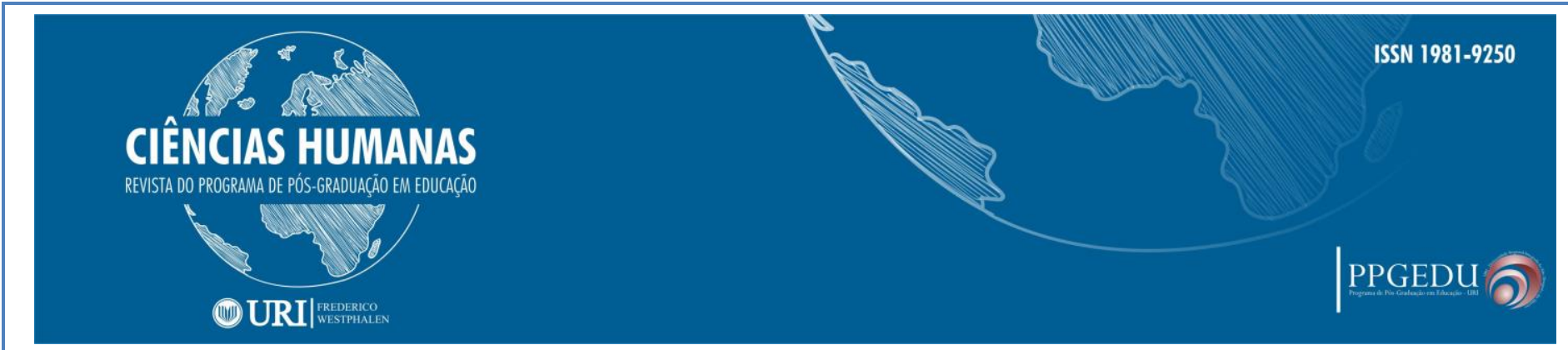

normalmente, é que ainda não existe consenso quanto a uma política de avaliação da aprendizagem no nível superior, e a sua prática ao longo do curso continua em modelos tradicionais em que se predomina o sentido de avaliar como medir e para aprovar ou reprovar.

Observou-se na literatura visitada que, nos últimos anos, essa realidade vem sendo alterada, com diversas práticas de metodologias ativas, mudando gradativamente o cenário das salas de aula e das avaliações, com o apoio das tecnologias. O ENADE, como avaliação ao final do curso (atualmente) que adota o modelo de avaliação por competências tem contribuído para essas mudanças. No ensino superior a avaliação da aprendizagem vem sendo feita desde a institucionalização do ENADE com foco no desempenho do estudante e atrelado ao conceito de competência, que envolve o saber fazer além de atitudes e habilidades, conforme teorizado pelos autores utilizados como amparo teórico, dentre eles Perrenoud (1998). Até mesmo na Educação Básica, a teoria das competências vem fundamentando o ENEM e a Base Nacional Curricular Comum (BNCC).

O conceito de competência marca a discussão pedagógica e social das últimas décadas e pode ser identificado no texto da LDB, $\mathrm{n}^{\circ}$ 9394, em vigor, especialmente quando se estabelecem as finalidades gerais do Ensino Fundamental e do Ensino Médio, nos Artigos 32 e 35 da referida lei. Desde as décadas finais do século XX e, ao longo deste início do século XXI, o foco no desenvolvimento de competências tem orientado a maioria dos Estados e Municípios brasileiros e diferentes países na construção de seus currículos, como descrito no próprio documento da BNCC. E esse também tem sido o enfoque adotado nas avaliações internacionais da Organização para a Cooperação e Desenvolvimento Econômico (OCDE), que coordena o Programa Internacional de Avaliação de Alunos (Pisa, na sigla em inglês)11, e da Organização das Nações Unidas para a Educação, a Ciência e a Cultura (Unesco, na sigla em inglês), que instituiu o Laboratório Latino-americano de Avaliação da Qualidade da Educação para a América Latina (LLECE, na sigla em espanhol).

\begin{tabular}{c|c|c|c}
\hline Rev. Ciências Humanas & Frederico Westphalen, RS & Pg. 04 - 26 & Set./dez. 2018 \\
\hline \multicolumn{2}{c}{ Recebido em: 21/11/2018 } & Aceito em: 04/01/2019 \\
\hline
\end{tabular}




\section{CIÊNCIAS HUMANAS}

REVISTA DO PROGRAMA DE PÓS-GRADUAĞ̈O EM EDUCAĞ̄o

\section{(1) URI|}

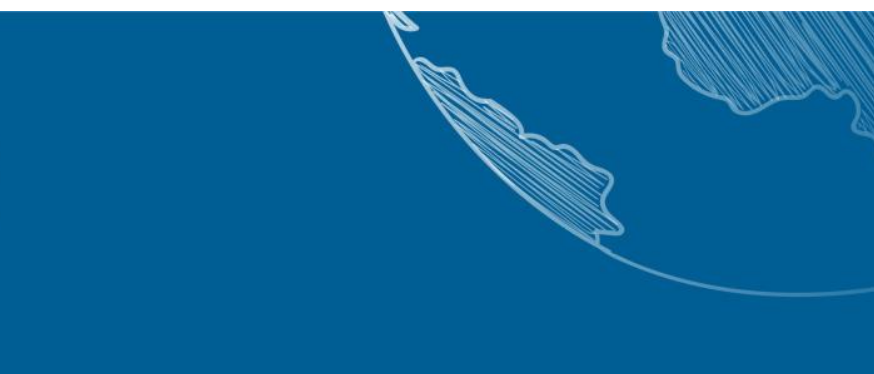

COMPLEXIDADE E ABRANGÊNCIA DA AVALIAÇÃO NA EDUCAÇÃO SUPERIOR

De início, cabe repetir que o SINAES, instituído pela Lei $\mathrm{n}^{\circ} 10.861$, tem por finalidade "assegurar processo nacional de avaliação das instituições de educação superior, dos cursos de graduação e do desempenho acadêmico de seus estudantes" (BRASIL, 2004). Em seu artigo $1^{\circ}$, o documento da Lei $n^{\circ} 10.861 / 2004$ define as finalidades do Sinaes:

[...] a melhoria da qualidade da educação superior, a orientação da expansão da sua oferta, o aumento permanente da sua eficácia institucional e efetividade acadêmica e social e, especialmente, a promoção do aprofundamento dos compromissos e responsabilidades sociais das instituições de educação superior, por meio da valorização de sua missão pública, da promoção dos valores democráticos, do respeito à diferença e à diversidade, da afirmação da autonomia e da identidade institucional (BRASIL, 2004, art. $1^{\text {o }}$ ).

Desmembrando o conteúdo deste texto, observa-se a complexidade e a abrangência do Sistema de Avaliação do Ensino Superior, tendo como meta direcionadora a melhoria da qualidade da educação superior, como segue:

- [...] orientação da expansão da sua oferta;

- [...] aumento permanente da sua eficácia institucional;

- [...] efetividade acadêmica e social;

- [...] promoção do aprofundamento dos compromissos;

- [...] responsabilidades sociais das instituições de educação superior, por meio da valorização de sua missão pública, da promoção dos valores democráticos, do respeito à diferença e à diversidade, da afirmação da autonomia e da identidade institucional (BRASIL, 2004).

De acordo com sua estruturação, o SINAES considera para a avaliação aspectos que estão em torno de três componentes considerados como principais: a avaliação das instituições, dos cursos e do desempenho dos estudantes e quanto aos aspectos que são avaliados em torno desses eixos: o ensino, a pesquisa, a extensão, a responsabilidade 


\section{CIÊNCIAS HUMANAS}

REVISTA DO PROGRAMA DE PÓS-GRADUAĞ̈O EM EDUCAĞ̄o

\section{(1) URI|}

social, o desempenho dos alunos, a gestão da instituição, o corpo docente, as instalações e vários outros aspectos (INEP, 2011).

O Sinaes trata-se de uma estrutura que possui como objetivo assegurar o processo nacional de avaliação das instituições de educação superior, dos cursos de graduação e do desempenho acadêmico de seus estudantes (BRASIL, 2004). Para cumprir com suas finalidades, o Sinaes possui uma série de instrumentos complementares, sendo: a autoavaliação, a avaliação externa, o Exame Nacional de Desempenho de Estudantes (ENADE), a avaliação dos cursos de graduação e instrumentos de formação e cadastro, todos com a finalidade de traçar um cenário da qualidade dos cursos e das Instituições de Educação Superior (IES) no país (INEP, 2011).

De início, é importante ressaltar que, no Brasil, já são três décadas de prática de avaliação da educação superior. Entre reformulações e ajustes, os programas avaliativos foram sendo reestruturados ao longo dos anos (especificamente desde o Provão - 1983) e, a partir de proposta elaborada pela Comissão Especial de Avaliação (CEA), foi implantado, no ano de 2004, o Sistema Nacional de Avaliação da Educação Superior (Sinaes).

O Sinaes é formado por três componentes principais: a) a avaliação das instituições; b) avaliação dos cursos; c) avaliação do desempenho dos estudantes. Com um planejamento detalhado, o Sinaes, por meio de um conjunto diversificado de instrumentos, procurar monitorar o ensino, a pesquisa, a extensão, a responsabilidade social, o desempenho dos alunos, a gestão da instituição, o corpo docente, as instalações e vários outros aspectos relacionados à sustentabilidade da instituição, inclusive a financeira.

Esse processo de avaliação deve ser visto a partir de um conjunto de indicadores de qualidade que atuem de forma integrada, além de instituir um caráter público quanto aos procedimentos adotados e seus resultados, considerando a participação do corpo docente, discente, técnico administrativo da IES, sociedade civil por meio de seus representantes e, por fim, estabelecer a continuidade do processo avaliativo. Com a consolidação do Sistema Nacional de Avaliação do Ensino Superior - Sinaes, a 


\section{CIÊNCIAS HUMANAS}

REVISTA DO PROGRAMA DE PÓS-GRADUAĞ̈O EM EDUCAĞ̄o

\section{(1) URI|}

avaliação tornou-se, no Brasil, uma política de Estado.

Os resultados do ENADE, aliados às respostas do questionário do estudante, constituem-se insumos fundamentais para o cálculo dos indicadores de qualidade da educação superior: Conceito ENADE, conceito Preliminar de Curso (CPC) e Índice Geral de Cursos Avaliados da Instituição (IGC), normatizados pela portaria número 40 de 2007, republicada em 2010 e revogada em 2017.

Esses indicadores, com caráter avaliativo, mensuram a qualidade dos cursos e das instituições do país, sendo utilizado tanto para o desenvolvimento de políticas públicas da educação superior quanto como fonte de consultas pela sociedade (BRASIL/MEC, 2011) no que se refere aos serviços educacionais prestados e à sua função social e política.

Entretanto, esse processo tem sido elogiado por tornar possível acompanhar o andamento do aprendizado dos estudantes universitários no país e fornecer indicadores e insumos para uma visão geral sobre a qualidade e o aproveitamento do ensino superior brasileiro, mas também recebe diversas críticas. Para o autor, a inserção da avaliação no contexto das políticas sociais e de educação, a partir das mudanças de um Estado interventor para um Estado avaliador, tratou-se de um reordenamento ocorrido com a descentralização do Estado e a busca de eficiência e qualidade e que no Brasil destacouse pela implementação de programas para controle de resultados dos alunos e das instituições de ensino.

Nesse cenário, o referido autor afirma que a avaliação passou a ser um elemento essencial na formulação e gestão de políticas no setor, estando ligada de forma íntima a formulação de políticas, em particular, às educacionais. Na análise de Catani, Dourado e Oliveira (2002), com as reformas introduzidas na educação superior brasileira na década de 1990, as políticas e a gestão da educação superior passaram a ter a atenção de pesquisadores devido ao processo de regulação sistematizado que se verificou a partir de então.

Cabe destacar que, embora o foco das pesquisas gire em torno dos mais diversos eixos temáticos, as questões sobre expansão, tanto pública quanto privada da educação superior, privatização, massificação e democratização, nesse nível de ensino, têm 


\section{CIÊNCIAS HUMANAS}

REVISTA DO PROGRAMA DE PÓS-GRADUAĞ̈O EM EDUCAĞ̄o

\section{(1) URI|}

predominado, sendo analisadas com foco na regulação no ensino superior, sendo a política de avaliação o principal mecanismo para a regulação.

\section{CONSIDERAÇÕES FINAIS}

Por meio do apresentado neste artigo, é possível observar que a fase contemporânea busca por si uma forma ideal de avaliar, levando em consideração tudo que já foi vivido e reverenciado no processo histórico da avaliação, resumidamente descrito neste texto. Na contemporaneidade, observa-se uma busca por formas mais justa, inteligente, criativa e eficaz de avaliação. Nesse sentido, justificam-se as reflexões aqui apontadas, uma vez que a compreensão dos processos históricos contribui para incitar reflexões e mudanças em busca de inovação nas práticas educativas contemporâneas e, consequentemente, também nos processos avaliativos.

Não foi a intenção retomar a trajetória histórica da educação brasileira, mas apenas frisar que a história da educação é marcada por diferentes períodos e, como processo imbricado nas práticas educativas, a avaliação também seguiu a mesma trajetória histórica.

Dessa forma, a avaliação da aprendizagem caminhou atrelada aos grandes desafios do processo pedagógico, nos diferentes níveis de ensino, havendo entre os autores uma diversidade de entendimentos a respeito do conceito de avaliação e, dessa forma, a avaliação, que é parte integrante do processo ensino e aprendizagem.

Atualmente, a avaliação da aprendizagem tem foco do desempenho do estudante e, no caso do ensino superior, é realizada pelo ENADE, evidenciando a sua coerência com as concepções de educação predominantes nos respectivos momentos históricos atuais, cuja tendência predominante é a formação para o desenvolvimento de competências e habilidades, conforme Lei $n^{\circ}$ 10.861/2004, que institucionalizou o SINARES.

Dessa forma, ao longo dos últimos anos, a avaliação vem ganhando espaço muito amplo e também se aperfeiçoando/ diversificando diante de projetos e propostas 


\section{CIÊNCIAS HUMANAS}

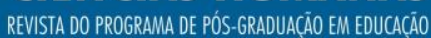

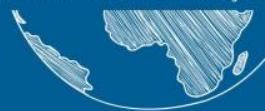

(1) URI|

pedagógicas mais modernas, tendo em vista o principal objetivo do SINAES, que é a melhoria da qualidade da educação.

\section{REFERÊNCIAS}

ABRAMOWICZ, M. Avaliação da aprendizagem: como trabalhadores-estudantes de uma faculdade particular noturna vêem o processo - em busca de um caminho. 1990. Tese (Doutorado) - Pontifícia Universidade Católica de São Paulo. São Paulo, 1990. 1996.

Avaliando: A avaliação da aprendizagem - Um novo olhar. São Paulo: Lúmen,

BRASIL. Lei no 13.005, de 25 de junho de 2014. Aprova o Plano Nacional de Educação - PNE e dá outras providências. Diário Oficial da União, Brasília, 26 de junho de 2014. Disponível em: <http://www.planalto.gov.br/ccivil_03/_ato20112014/2014/lei/113005.htm> Acesso em: 23 mar. 2018.

CNE. Parecer $n^{\circ} 7$, de 7 de abril de 2010. Diretrizes Curriculares Nacionais Gerais para a Educação Básica. Diário Oficial da União, Brasília, 9 de julho de 2010, Seção 1, p. 10. Disponível em: http://portal.mec.gov.br/dmdocuments/rceb004_10.pdf Acesso em: 23 mar. 2017.

Lei $\mathbf{n}^{\circ}$ 9.394, de 20 de dezembro de 1996. Estabelece as diretrizes e bases da educação nacional. Diário Oficial da União, Brasília, 23 de dezembro de 1996. Disponível em: http://www.planalto.gov.br/ccivil_03/LEIS/L9394.htm . Acesso em: 23 mar. 2018.

. Base Nacional Comum Curricular (BNCCC). Disponível em:

http://basenacionalcomum.mec.gov.br/wpcontent/uploads/2018/04/BNCC_EnsinoMedio_embaixa_site.pdf PERRENOUD, Philippe. MAGNE, B. C. Construir: as competências desde a escola. Porto Alegre: Artmed, 1998.

LEI No 10.861, de 14 de abril de 2004. Institui o Sistema Nacional de Avaliação da Educação Superior - SINAES e dá outras providências. Disponível em: http://www.planalto.gov.br/ccivil_03/_ato2004-2006/2004/lei/110.861.htm Acesso: 12 set. 2018.

LEI No 13.005, de 25 de junho de 2014. Aprova o Plano Nacional de Educação - PNE e dá outras providências. Disponível em: 


\section{CIÊNCIAS HUMANAS}

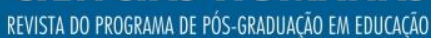

\section{(1) URI|}

http://www.planalto.gov.br/ccivil_03/_ato2011-2014/2014/lei/113005.htm Acesso: 12 set. 2018.

Base Nacional Comum Curricular - Educação é a Base - Ensino Medio. Disponível em: <http://basenacionalcomum.mec.gov.br/>. Acesso em: 24 at. 2018.

Lei $n^{\circ}$ 9.394, de 20 de dezembro de 1996. Estabelece as diretrizes e bases da educação nacional. Disponível em: < http://www.planalto.gov.br/CCIVIL_03/leis/L9394.htm>. Acesso em: 02 mar. 2018.

SINAES - Sistema Nacional de Avaliação da Educação Superior: da concepção à regulamentação/Instituto Nacional de Estudos e Pesquisas Educacionais Anísio Teixeira. 4. ed., ampl. - Brasília: Instituto Nacional de Estudos e Pesquisas Educacionais Anísio Teixeira, 2007.

INEP. Análise dos resultados do exame nacional de desempenho dos estudantes das áreas avaliadas em 2005 e 2008, com ênfase nos cursos de arquitetura e urbanismo, engenharia e pedagogia. V 1. Brasília, DF: Inep, 2015.

.INEP. Avaliação das instituições de educação superior. Brasília, 2011. Disponível em: <http://portal.inep.gov.br>. Acesso em: 15 abr. 2018.

CARMINATTI, S. S. H.; BORGES, M. K. Perspectiva da Avaliação da Aprendizagem na Contemporaneidade. Est. Aval. Educ., São Paulo, v. 3, n. 52, p. 160-178, mai. ago. 2012.

FERNANDES, D. Avaliação das aprendizagens: desafios às teorias, práticas e políticas. Cacém: Texto Editores, 2005.

FERNANDES, D. Avaliação das Aprendizagens: Desafios às Teorias, Práticas e Políticas. Colecção Educação Hoje. Porto: Textos Editores, Lta, 2009.

GUBA, E. G.; LINCOLN, Y. S. Fourth generation evaluation. Newbury Park, CA: Sage, 1989. (Trad. Livre)

GUBA, E.; LINCOLN, Y. Avaliação de quarta geração. Campinas: Editora Unicamp, 2011. (Tradução no Brasil)

LIBÂNEO, J. C. (1992). Didática. São Paulo: Cortez, 1992.

LIMA, J. do R. O Processo histórico da avaliação. Disponível em:

$<$ http://www.administradores.com.br/artigos/economia-e-financas/o-processohistoricoda-avaliacao/48584/> Acesso em: Março de 2015.

LUCKESI, C. C. Avaliação da aprendizagem escolar: estudos e proposições. 6.ed. São Paulo: Cortez, 1997. 


\section{(1) URI|}

Organização das Nações Unidas. Transformando Nosso Mundo: a Agenda 2030 para o Desenvolvimento Sustentável.

Disponível em: http://www.br.undp.org/content/dam/brazil/docs/agenda2030/undp-brAgenda2030-completo-pt-br-2016.pdf . Acesso em: 7 nov. 2017.

PERRENOUD, P. Avaliação: da excelência à regularização das aprendizagens: entre duas lógicas. Porto Alegre, Artmed, 1998.

ROPÉ, F.; TANGUY, L. (Org.) Saberes e competências: o uso de tais noções na escola e na empresa. Campinas: Papirus, 1997.

STUFFLEBEAM, D. L. The relevance of the CIPP evaluation model for educational accountability. Journal of Research and Development in Education, 5(1), 19-25, 1971(Trad. Livre).

VASCONCELLOS, C. S. Avaliação: concepção dialética-libertadora do processo de avaliação escolar. São Paulo: Libertad, 2000. 